\title{
CAN OBJECTIVISTS ACCOUNT FOR SUBJECTIVE REASONS?
}

\author{
Daniel Wodak
}

7 He Distinction BETWEen objective and subjective reasons is quite intuitive, in part because the two seem to play different roles in normative

I thought. If a blue pill would cure Anna's disease, there is an objective reason for her to take it. If Anna believes that only the red pill would cure her, there is a subjective reason for her to take it. And if Anna received misleading evidence that taking the red pill causes nausea, there would be a less weighty subjective reason not to take it. The objective reasons bear on what Anna objectively ought to do (take the blue pill). The subjective reasons bear on what she subjectively ought to do (take the red pill). Objective and subjective reasons also seem to play distinct roles from the second-person standpoint: the objective reasons bear on what a fully informed interlocutor should advise Anna to do, but do not bear on what that interlocutor should criticize her for doing, and vice versa for subjective reasons, which bear on whether a fully informed interlocutor should criticize Anna, but not on what that interlocutor should advise her to do.

If there are objective and subjective reasons, how are they related? Are they species of a genus? If so, what is the differentia? Does one reduce to the other? If so, how does the reduction go? Perhaps the most popular view on this issue is objectivism, which holds that subjective reasons reduce to objective reasons.

My main aim in this paper is to offer two objections to objectivist accounts of subjective reasons. They concern probability and possibility. A secondary aim is to offer a diagnosis of why objectivists face these two objections.

A quick methodological point will be helpful before we begin. I appeal to intuitions about existential claims about subjective and objective reasons. These can be challenged. One way to resolve such challenges-which I apply extensively below - is to consider the distinct roles that objective and subjective reasons play in normative thought. If one contends that $p$ is a subjective (objective) reason to $\phi$, it should play the same kind of roles as other plausible candidates for subjective (objective) reasons to $\phi$. For instance, a putative objective reason for Anna to take the blue pill should play the same kind of roles as the fact that 
the blue pill will cure her: it should bear on whether she objectively ought to take the pill, and whether a fully informed interlocutor should advise her to do so. ${ }^{1}$ I consider this to be a simple litmus test. It might admit of exceptions. But none of the cases I consider below is an exception to the rule. If one wishes to contend otherwise, the onus is on them to defend this.

\section{OBJECTIVISM}

Let us start by homing in on objectivism. Various objectivist accounts of subjective reasons have been developed and defended by Mark Schroeder, Jonathan Way, Derek Parfit, Eric Vogelstein, Daniel Whiting, Kurt Sylvan, and others. The central objectivist commitment is that we should analyze subjective reasons in terms of objective reasons. Most objectivists commit to a fairly narrow version of this view wherein we analyze all subjective reasons to $\phi$ directly-that is, in terms of objective reasons to $\phi .{ }^{2}$ This will be part of my diagnosis of why extant forms of objectivism face the problems below. But let us not jump ahead.

It is easier to understand objectivism by focusing on a particular account. Many prominent objectivists have been attracted to counterfactual analyses:

For $R$ to be a subjective reason for $X$ to do $A$ is for $X$ to believe $R$, and for it to be the case that $R$ is the kind of thing, if true, to be an objective reason for $X$ to do $A .^{3}$

1 That objective and subjective reasons bear distinct relations to objective and subjective "oughts" is widely accepted: "some reasons will be facts of the sort that explain what one objectively ought to do, while other reasons will be facts of the sort that explain what one subjectively ought to do" (Wedgwood, “The Pitfalls of 'Reasons,"” 128). The former are objective reasons, the latter subjective reasons. Mark Schroeder appeals to something like this second role as a distinguishing feature of objective reasons throughout "Having Reasons." He formulates it as a counterfactual test: the question is whether "a fully informed and beneficent bystander would take [the putative objective reason] into account in advising" the agent to perform the relevant act (59). I prefer my formulation, but nothing hangs on this.

2 This constraint is evident in the quotation from Schroeder below; I believe it is also accepted by Way and Parfit, along with other objectivists. For instance, here is Vogelstein's view: "A subjective reason for one to $\phi$ is a proposition $\mathrm{p}$ such that the members of some consistent subset of one's $a$ jointly entail (1) that $p$ is true, and (2) that the fact that $p$ is an objective reason for one to $\phi$ " (Vogelstein, "Subjective Reasons," 250).

3 Schroeder, Slaves of the Passions, 14. See also Schroeder, "Means-End Coherence, Stringency, and Subjective Reasons," 233, for his similar "subjective reason test": " $X$ has a subjective reason to do $A$ just in case she has some beliefs which have the property, if they are true, of making it the case that $X$ has an objective reason to do $A$ "; see also his converse test at 245 . 
Subjective reasons [are] believed propositions that would be reasons if true. ${ }^{4}$ If we have certain beliefs about the relevant, reason-giving facts, and what we believe would, if it were true, give us some reason, ... such beliefs give us an apparent reason. ${ }^{5}$

In what follows I focus primarily on the following version of this view:

C: $p$ is a subjective reason for $A$ to $\phi$ iff and because (a) $A$ believes $p$, and (b) if $p$ were true, $p$ would be an objective reason for $A$ to $\phi$.

To illustrate: that the red pill would cure her is a subjective reason for Anna to take the red pill iff and because she believes this proposition, and if it were true that fact would be an objective reason to take the red pill.

Of course, $\mathrm{C}$ is not the only game in town. So we will also consider ways that $\mathrm{C}$ can be revised, as well as Whiting's and Sylvan's alternatives to C.

\section{PROBABILITY}

Now let's consider how $\mathrm{C}$ handles cases involving (subjective) probability. To begin, consider Baqir. He knows that the blue pill would cure his disease. There are two other pills: red and green. Baqir knows that one of them will cure his disease and improve his eyesight, and the other will kill him. In fact, the red pill would kill Baqir and the green pill would cure and improve him. But Baqir does not know this. He justifiably assigns a .5 credence to each possibility.

Counterfactual analyses like $\mathrm{C}$ seem to deliver the right results about cases like Baqir's. Baqir believes that the blue pill will cure him. If that proposition were true (which it is) it would be an objective reason to take the blue pill.

There the discussion of probability typically ends. This is unfortunate, as it only captures one class of cases: when there is subjective reason for agents to be cautious instead of risky. What about when there is subjective reason for agents to be risky rather than cautious? Can $\mathrm{C}$ get these cases right?

Consider Carla. She knows that if she does not take the purple pill, she will die painlessly. But she does not know what the purple pill will do. She justifiably assigns a .5 credence to two possibilities: it will cure her completely, or it will kill her painfully. In fact, it will kill her painfully. Here are two data points:

Datum $_{1}$ : There is a subjective reason for Carla to take the pill.

Datum $_{2}$ : There is no objective reason for Carla to take the pill.

4 Way, "Two Accounts of the Normativity of Rationality," 3.

5 Parfit, On What Matters, 1:111. 
These existential claims are quite intuitive, though they can be challenged.

For now, let us take them as given and see whether they can be accommodated by $\mathrm{C}$. What is the subjective reason for Carla to take the pill? The most plausible answer, I believe, is a claim about subjective chance that we can call:

Probability: There is a 5 chance that the purple pill will cure Carla.

Is this response available to those who accept $C$ ? One immediate issue is whether Probability is truth-apt. Many take our discourse about subjective chance to be non-factive; they take subjective probabilities to be nothing more than expressions of creedal states. This is a problem for $\mathrm{C}$, which holds that Probability is a subjective reason for Carla to take the pill only if Carla believes it, and if it were true, it would be an objective reason for her to take the pill. ${ }^{6}$

Let us put this issue aside. Grant that Probability can be true. If that is the case, presumably it is true. This generates a far more interesting problem for $\mathrm{C}$. If $\mathrm{C}$ is true, Probability is a subjective reason to take the pill only if it is a counterfactual objective reason to take the pill. But if Probability is true, it is a counterfactual objective reason to take the pill only if it is an objective reason to take the pill in the actual world. And Probability is not an objective reason to take the pill in our world. To hold otherwise is to deny Datum 2 .

In case the middle step in this reasoning is unclear, the basic idea is that counterfactuals tell us what would be the case if the antecedent were true. So the consequent is true if the antecedent is true. And the antecedent of the relevant counterfactual, Probability, is true (supposing, again, that it is truth-apt). So if the counterfactual is true, the consequent must be true, too. But the consequent is the claim that Probability is an objective reason to take the pill.

A brief aside. It is worth noting something about the broader dialectical import of the specific point above. Arguably, one objectivist alternative to $\mathrm{C}$ is the Factoring Account, which was raised and rejected by Schroeder, and has since been defended at length by Errol Lord. ${ }^{7}$ The crucial commitment of the Fac-

6 See the discussion of vacuity in section 3, below, for more on why this would pose an issue.

7 See especially Schroeder's "Having Reasons," 58, in which he argues that "the Factoring Account is wrong. In the relevant sense, reasons you have are not things which are, independently of you, reasons, and which moreover, you have. There are simply two reason relations at stake." Since the Factoring Account does not take there to be a second reason relation, it is unclear whether it counts as a form of objectivism. I say that Lord has defended the factoring account, but there is a way of reading his view where it does not aim to analyze the notion of subjective reasons, and so is not objectivist in the sense I am concerned with. This is suggested in, e.g., Lord, "Having Reasons and the Factoring Account," 290, and "The Coherent and the Rational," 156. In personal communication, however, Lord clarified that he intends to analyze subjective reasons in terms of objective reasons that we have or pos- 
toring Account is that subjective reasons for $A$ to $\phi$ are analyzable in terms of objective reasons for $A$ to $\phi$ and possession: $p$ is a subjective reason for $A$ to $\phi$ iff $p$ is an objective reason for $A$ to $\phi$ and $A$ has $p$. What led Schroeder to reject the Factoring Account, and defend $\mathrm{C}$ instead, is that the former insists that if $\mathrm{p}$ is a subjective reason for $A$ to $\phi$, then $p$ is an objective reason for $A$ to $\phi$. But C inherits a similar commitment: if $p$ is a subjective reason for $A$ to $\phi$ and $p$ is true, then $p$ is an objective reason for $A$ to $\phi$. Objectivists had good grounds for wanting an account that allowed objective and subjective reasons to come apart, but $\mathrm{C}$ does not actually deliver that with true propositions. ${ }^{8}$

Now back to our main thread. How should a proponent of $\mathrm{C}$ respond to

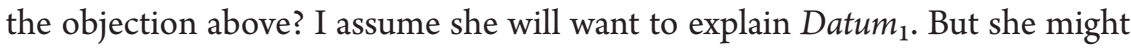
challenge Datum ${ }_{2}$. Schroeder argued that "negative existential intuitions about reasons are not to be trusted." Some might take this to mean that they should never be trusted. But that would be a mistake. Schroeder's explanation for why they should not be trusted turns on pragmatic implicatures about reasons with low weights. He offered a simple test for whether this applies to a given claim:

If I tell you that there is a reason for you to do something that there are only poor reasons for you to do, what I say will sound wrong. But-first prediction-it will sound less wrong if I tell you what the reason is, because doing so will remove the pragmatic reinforcement of the standing presumption that I have only relatively good reasons in mind. And second, if I then tell you that I don't think it is a particularly weighty reason, I should be able to cancel the presumption, and so the unintuitiveness of what I say should go down a second time.

Let us apply this to the case at hand. That there is an objective reason for Carla to take the pill sounds wrong. (This is why Datum ${ }_{2}$ seems true.) Does it sound less wrong if we identify the putative objective reason? The claim now is: that the purple pill has a .5 (subjective) probability of curing her is an objective reason to take the pill. This still seems wrong to me. The explanation for why, to be clear, is not because subjective chance is not part of the extra-mental world. Facts about

sess, and resists the terminology "subjective" only because it is associated with the notion of "reasons [that] are just a function of one's perspective, even when it is seriously deluded" (Lord, "What You're Rationally Required to Do and What You Ought to Do (Are the Same Thing!)," 14n25).

8 Schroeder argued that there is "the objective reason relation and the subjective reason relation, and the data give us no good reason to suspect that either is a restriction on the other, as the Factoring Account proposes" ("Having Reasons," 58). I will not discuss the Factoring Account further, but the objections below target it too.

9 Schroeder, Slaves of the Passions, 92. 
subjective mental states can be objective reasons for actions and attitudes. That a man has pathological desires is an objective reason for him to seek therapy, and for us to not vote him into the White House. So my claim is not that Probability cannot be an objective reason per se.

Rather, the claim I am making is that Probability is not an objective reason for Anna to take the pill. If that were the case, Probability should play similar roles to other plausible candidates for objective reasons for and against taking the pill. Objective and subjective normative notions play distinct roles in normative thought. Take Anna's case once more. That the blue pill will cure her is an objective reason for her to take the pill. It bears on whether she objectively ought to take it, and whether, knowing the facts, we should advise her to take it. Subjective reasons play different roles: since Anna believes that the red pill will cure her, we should not criticize Anna for taking the red pill. So which roles does Probability play? It does not have any bearing on whether she objectively ought to take the pill. Nor does it have any bearing on whether, knowing the facts, we should advise her to take the pill. These roles are played by the facts about what the pills do. But Probability does play some roles: it bears on whether we should criticize Carla if she takes the pill, for instance. So Probability is a plausible candidate for a subjective reason to take the pill, but not a plausible candidate for an objective reason for her to take the pill.

At this point, some might apply the second part of Schroeder's test. Maybe the problem is just that saying that Probability is an objective reason for Carla to take the pill implicates that it is a weighty objective reason for her to take the pill. So let us cancel that implicature: Probability is a very weak objective reason for Carla to take the pill. Surely this sounds better! So is Datum ${ }_{2}$ false?

I do not think so. If the above reasoning is right, Probability is not merely an outweighed objective reason. The point of distinguishing between objective and subjective reasons is that they play distinct roles. If the fact that the pill will kill her competes with Probability in determining what Carla objectively ought to do, and how all-knowing advisors ought to advise her to act, the distinction between objective and subjective reasons is a distinction without a difference.

This raises the question of why the claim above sounds better once the implicature is canceled. But that is fairly easy to explain. Mistakes can be more or less egregious. Saying that the fact that someone is your mother is a reason to torture her sounds very, very wrong. It sounds less wrong if you cancel the implicature that this is a weighty reason to torture her. But surely that does not mean that the implicature was the sole source of the problem!

So far we have seen that a proponent of $\mathrm{C}$ cannot accommodate the data by identifying Probability as the subjective reason for Carla to take the pill, and 
should not respond to this problem by denying the data. An alternative response is to accommodate the data by finding some other candidate for the subjective reason for Carla to take the pill. Notably, many other initially plausible candidates will raise the exact same problems as Probability. For instance, consider the following plausible conjecture: there is some evidence that justifies Carla's beliefs and credences; whatever that evidence is, it is the subjective reason for her to act. ${ }^{10}$ To fill this proposal out a little, let us imagine that the relevant evidence is testimony-Carla is justified in assigning her credences on the basis of what her reliable friend said. Now we can consider the following proposition:

Evidence: The reliable friend said that there is a .5 chance that the purple pill will cure Carla.

Alternatively, consider the plausible conjecture that Carla's doxastic states are the subjective reasons for her to act. ${ }^{11}$ Now we can consider the proposition:

Belief: Carla believes that there is a .5 chance that the purple pill will cure her.

Can a proponent of $\mathrm{C}$ say that Evidence or Belief is the subjective reason for Carla to take the pill? No: both initially plausible conjectures raise the exact same problems as Probability. Let us start with Evidence. If $\mathrm{C}$ is true, Evidence is a subjective reason to take the pill only if it is a counterfactual objective reason to take the pill. And since Evidence is true, that means it is a counterfactual objective reason to take the pill only if it is an objective reason to take the pill in the actual world. But according to Datum 2 , there is no objective reason to take the pill (in the actual world). As with Probability, one can try to challenge this datum by appealing to Schroeder's test, but we do not get better results when we apply this test to Evidence. It does not play the right roles to be an objective reason for her to take the pill. It has no bearing on whether she objectively ought to take the pill, or on whether, knowing the facts, we should advise her to take the pill. ${ }^{12}$ The same reasoning applies to Belief with even greater force: it is also true, and clearly fails to play the right roles to be an objective reason for her to take the pill. If merely believing that pills will cure you is an objective reason for you to take them, the distinction between objective and subjective reasons seems to be a distinction without a difference.

This shows that, to accommodate the data, the objectivist needs to find a very

I am grateful to an anonymous referee for suggesting this response.

11

I am grateful to an anonymous referee for suggesting this response. It has affinities with Dale Dorsey's view in “Objective Morality, Subjective Morality, and the Explanatory Question.”

If one doubts this, see the discussion of a similar proposal, Testimony, in section 3, below. 
different candidate for the subjective reason for Carla to take the pill. It should be a proposition such that Carla believes it and if it were true it would be an objective reason to take the pill; but it should not be a proposition that is actually true, lest we go through another round of the reasoning above. The best remaining candidates, I believe, will be propositions like the following:

Prejacent: The purple pill will cure Carla. ${ }^{13}$

Why will the best remaining candidates be propositions like Prejacent? Because it is clearly truth-apt, it is false (so it does not face the same problems as Probability, Evidence, and Belief), and if it were true it would be an objective reason to take the pill. The obvious bug is that Carla does not believe Prejacent, and C insists that $p$ is a subjective reason for Carla only if Carla believes that $p$. This necessary condition is explicitly embraced by Schroeder, Way, and Parfit in the passages quoted above. ${ }^{14}$ Plausibly, any alternatives to Prejacent that share its virtues will also share this vice; there does not seem to be any false proposition that Carla actually believes such that if it were true it would be an objective reason for her to take the pill.

As has been previously noted, other views about reasons have a similar bug in cases like Carla's, insofar as those views also require reasons to be believed (or known, or what have you). ${ }^{15} \mathrm{I}$ am not sure whether the bug poses a serious problem for these other views, which are not framed as objectivist accounts of subjective reasons. It may be open to those views to identify propositions like

13 In case this is unclear, I am calling this Prejacent to make a more general point. We have seen the difficulties objectivists face if they treat propositions like $\diamond p$ as a subjective reason to $\phi$, where $\diamond$ is an epistemic modal that scopes over what is called the prejacent: $p$. The most plausible move remaining is to treat the prejacent itself, $p$, as the subjective reason to $\phi$.

14 To be clear, the issue here is not that these passages were clumsily formulated. Lord notes that on Schroeder's view "a necessary condition for something to be a subjective reason is that one must believe the proposition that constitutes the subjective reason" (Lord, "Having Reasons and the Factoring Account," 291). See also Schroeder, "Means-End Coherence, Stringency, and Subjective Reasons," 245 , for a clear, specific case in which this necessary condition does serious work for Schroeder ("since Wynn does not have a belief about that, it does not figure among her subjective reasons"). In other work, Schroeder adopts a weaker necessary condition: a presentational attitude that $p$ is all that is required ("What Does It Take to 'Have' a Reason?"). I believe this revised position is still vulnerable to the objection pressed here, for the same reasons discussed by Wedgwood in "The Pitfalls of 'Reasons," 135.

15 See, in particular, Wedgwood, who objects that common views about the relation between normative and motivating reasons systematically overestimate "the centrality of outright belief" ("The Pitfalls of 'Reasons," 134); and see Schiffer, who objects that the widely held view that "one should act only on what one knows" is problematic in cases where an agent is "justified in acting on a partial belief" ("Interest-Relative Invariantism," 189-90). 
Probability as agents' believed (or known, or ...) reason for action. ${ }^{16}$ But this response is not available to views about subjective reasons such as $\mathrm{C}$.

It seems, then, that we must weaken the doxastic component of $\mathrm{C}$. What if we allow that $p$ is a subjective reason for Carla only if Carla has a credence above $n$ in $p$, where $n$ is specified at some value? What value would that be? It is easy to show that the relevant value for $n$ will have to be very low. There can be a subjective reason to act even when one only has a negligible credence in the relevant proposition. Just make Carla almost certain that the purple pill is a placebo: say she justifiably assigns a credence of .99 (or .999, or ...) to this proposition, and assigns a .005 (or .0005 , or ...) credence each to the propositions that it will cure her and that it will kill her painfully. Now the revised version of $C$ will not explain why there is a subjective reason for her to take the purple pill unless we allow that any positive credence will suffice.

The objectivist who most clearly embraces such a view is Vogelstein. ${ }^{17}$ It allows objectivists to take Prejacent to be a subjective reason for Carla to take the pill, and does not imply that Prejacent is an objective reason for her to take the pill (because Prejacent is false), so it accommodates our data points.

But this move comes with three serious costs. Vogelstein recognizes the first: it makes subjective reasons maximally proliferate. The consequences of acts are contingent. We should have credences between $o$ and 1 in contingent truths. So for almost any idiotic action, agents should have some positive credence that it will cure Carla, or bring about world peace, or what have you. So as Vogelstein says, "we have subjective reasons to do almost anything." ${ }^{18}$ This does not worry Vogelstein, who insists that such subjective reasons have very low weights, and wields Schroeder's claims about intuitions about negative existential claims. I do not think that Vogelstein's position here seems plausible if we apply the methodological point with which we started. But I do not want to pursue this point as I believe that this form of objectivism faces more damning problems.

The second serious cost is that this form of objectivism misidentifies the rel-

For instance, that is how Hawthorne and Stanley respond to Schiffer in "Knowledge and Action," 136, arguing that contra Schiffer (and, in effect, Wedgwood in "The Pitfalls of 'Reasons," 136), agents can believe or know Probability without having an implausible degree of conceptual sophistication. Neither Schiffer nor Wedgwood considers the objection that Probability is not an objective reason for action.

17 Dorsey endorses a similar view of subjective reasons in "Objective Morality, Subjective Morality, and the Explanatory Question." Dorsey argues that "disbelieved propositions might themselves constitute subjective reasons" (11), and recognizes that his account proliferates subjective reasons (12). Many of my objections to Vogelstein's view apply equally to Dorsey's more complicated position.

Vogelstein, “Subjective Reasons,” 247-48. See note 2, above. 
evant subjective reasons. Even if the analysis gets the result that there is a subjective reason in these cases $\left(\right.$ Datum $\left._{1}\right)$, it gets the wrong result about which proposition is a subjective reason for Carla to take the pill. The subjective reason is that there is a .5 probability that the pill will cure her, not that the pill will cure her. It is Probability, not Prejacent. After all, when we compare Anna and Carla, it is intuitive that they have quite different subjective reasons to act because Anna believes that the pill will cure her while Carla only believes that the pill might cure her. This shows up clearly when we consider what proposition would play the relevant role in normative thought: in explaining why they should not be criticized if they take the pill, we would appeal to something like Prejacent in Anna's case and something like Probability in Carla's case. ${ }^{19}$

The final serious cost is that $\mathrm{C}$ now commits us to an atomic rather than a holistic view. To bring this into focus, consider one final variant on Carla's case. Say she was justifiably almost certain that the pill would kill her painfully, but still had some positive credence that it would cure her. Is there still a subjective reason for her to take the pill? On atomic views, there is: all that matters is her credence in the atomic proposition. On holist views, there is not: what matters is the overall distribution of probabilities over possible outcomes, not the assignment of a probability to a single possible outcome. In other words, holism holds that propositions like "the purple pill might cure Carla" can be a reason to take the pill in one context (in which the subjective chance that the pill will kill her painfully is low) but not be a subjective reason to perform the same action in another context (in which the subjective chance that the pill will kill her painfully is high); the atomist denies that this is possible. ${ }^{20} \mathrm{I}$ am not sure whether atomism or holism is true. But it strikes me that we should have an account of what it is to be a subjective reason that allows for both views to be coherently stated. Counterfactual analyses like Vogelstein's do not have this feature. Chaos ensues once we plug distributions of probabilities over (logically inconsistent) possible outcomes into the antecedents of counterfactuals. ${ }^{21}$

So far I have argued that $\mathrm{C}$ faces serious problems with probability. This point is at least somewhat important on its own. But it becomes all the more important once we note that objectivists who eschew counterfactual analyses face the same problem—or, at least, a problem with the same structure.

By "something like Probability," I mean to include Evidence or Belief, since these propositions can plausibly also play the same roles as subjective reasons for Carla to take the pill.

I use the term holism because this view dovetails nicely with Jonathan Dancy's version of value holism, according to which, "For any $x$ that has value in one context, $x$ may have a different value or none at all in other contexts" (“The Particularist's Progress," 13 ). 
Consider Sylvan's view, according to which $p$ is a subjective reason for $A$ to $\phi$ iff and because $p$ is an "apparent fact" that $A$ is competently attracted to treating like an objective reason to $\phi .{ }^{22} \mathrm{I}$ am attracted to this view. But how does it apply to Carla's case? What is the subjective reason for her to act?

Sylvan might say: the answer is Probability. We supposed that Probability is truth-apt. In a similar vein, let us suppose that it is an "apparent fact." For Sylvan, Probability is a subjective reason to take the pill only if Carla is competently attracted to treating it like an objective reason to take the pill. We saw above that, for $\mathrm{C}$, Probability is a subjective reason to take the pill only if it is an objective reason to take the pill, which is problematic because it does not play the right kind of roles to plausibly be an objective reason to take the pill. On that same basis, we can say that Carla is not competently attracted to treat Probability like an objective reason to take the pill. (The same holds for propositions like Probability, such as Evidence and Belief.) So for Sylvan, as for C, Probability cannot be Carla's subjective reason to take the pill.

What about Prejacent? This would be an objective reason if it were true. But Sylvan's view faces the same problem as $\mathrm{C}$ here: Carla can have a subjective reason to take the pill even when her credence in Prejacent is .5, or 0.00005 , or what have you. (Keep in mind the variations on the case above.) It is hard to see how Prejacent can be an "apparent fact" to Carla when she believes that it is almost certainly false. So for Sylvan, Prejacent is not a subjective reason.

In sum, counterfactual analyses and other forms of objectivism struggle to explain the data about subjective reasons in cases involving probability. Why has the problem been neglected? The whole point of introducing a distinction between objective and subjective reasons is that the facts can come apart from our perspective on the facts - subjective reasons, in Whiting's wonderful phrase, are introduced to "keep things in perspective." However, objectivists have only focused on how false beliefs cause the two to come apart. They have ignored how our perspectives systematically come apart from the facts due to our uncertainty.

\section{POSSIBILITY}

At one level of description, the first objection has a simple structure. There is a subjective reason to $\phi$. That reason is either a complex proposition (Probability), or a proposition embedded within it (Prejacent). But both of these options raise serious problems for current forms of objectivism. The most interesting part of this objection is the explanation for why, on current forms of objectivism, that complex proposition (Probability) cannot be a subjective reason to $\phi$.

22 Sylvan, "What Apparent Reasons Appear to Be." 
At that level of description, the structure of the second objection is the same. So is the problem raised by the complex proposition. The most interesting, and distinct, part of this objection will be the explanation for why, on current forms of objectivism, the relevant embedded proposition cannot be a subjective reason.

That is a fairly abstract preamble. So let us jump into some cases. Consider Duquan. He is taking an exam that he must pass, but that requires him to answer every question correctly. And he wants to pass at all costs. He is stuck on one question: "Name one true philosophical theory." Duquan skipped his philosophy seminars, but his reliable friend told him that modal realism is true. So he answers, "Modal realism: all possible worlds are real." Unfortunately, modal realism is false. Indeed, it is necessarily false. So he fails the exam.

A slight variation on this case will ultimately be more revealing. Consider Emiliano. He is in the same position as Duquan, except that (a) his reliable friend said that error theory is true, and (b) Emiliano is one of those wonderful students who cares most about getting things right—he wants to assert truths, and to pass by offering correct answers. So Emiliano answers, "Error theory: there are no objective reasons." Error theory is necessarily false. So he fails, too.

Let us introduce two data points that are quite intuitive, albeit challengeable:

Datum $_{3}$ : There was a subjective reason for Duquan/Emiliano to answer "modal realism"/"error theory" in the exam.

Datum $_{4}$ : There was no objective reason for Duquan/Emiliano to answer "modal realism"/"error theory" in the exam.

For now, let us take these data points as given and ask whether they can be accommodated by $\mathrm{C}$. What was the relevant subjective reason? As in section 2, the best candidates are a complex proposition (in this case, the testimony) and a proposition embedded within it (in this case, the content of that testimony):

Testimony: The reliable friend said that modal realism/error theory is true.

Content: Modal realism is true/error theory is true.

I am agnostic about which proposition is the better candidate for the relevant subjective reason. But that does not matter, as both generate problems.

Let us start with Testimony, as the problem here will be familiar. In fact, it will have exactly the same structure as the problem with Possibility, above. After all, Testimony is true. If Testimony is both true and a subjective reason to $\phi$, then according to $\mathrm{C}$ it must be an objective reason to $\phi$ in the actual world. This is counterintuitive. It makes Datum 3 true only if $\mathrm{Datum}_{4}$ is false. 
These intuitions about negative existential claims can be challenged. But Schroeder's test applies the same way to this case as it did to Carla's case above. Intuitively, Testimony does not seem to be an objective reason for Duquan and Emiliano to answer "modal realism"/"error theory" and thereby fail the exam, even if we cancel the implicature that it is a weighty objective reason. And as before, this claim can be bolstered by noting that Testimony does not seem to play the roles that objective reasons for such actions play: it does not bear on whether Duquan and Emiliano did what they objectively ought to do, or bear on what informed bystanders ought to advise them to do. If Duquan whispered to an all-knowing invigilator, "Should I answer 'modal realism'?" the fact that modal realism is false would clearly be relevant to whether he should answer no, but the fact that Testimony is true would clearly be irrelevant. Testimony is not merely outweighed by objective reasons (such as the fact that modal realism is false, which is a decisive objective reason not to answer "modal realism"); rather, Testimony fails to even compete with objective reasons at all.

Still, some may doubt that Testimony fails to compete with the objective reasons to answer "modal realism"/"error theory." And, indeed, they might doubt the similar verdicts about Probability, Evidence, and Belief in section 2. Without relying on contentious claims about the nature of objective and subjective reasons, what more can be said to bolster the claim that these facts do not play the right roles to be objective reasons for Carla, Duquan, and Emiliano to act?

One way to bolster these verdicts is to carefully distinguish the negative existential claims in question from nearby claims that are either irrelevant or implausible. The relevant negative existential claim is that Testimony is not an objective reason for Emiliano to answer "error theory" (and mutatis mutandis for Duquan). This should be distinguished from other plausible but irrelevant negative existential claims in the vicinity, such as the claim that it is not the case that Emiliano objectively ought to answer "error theory" (and mutatis mutandis for Duquan). These verdicts at the all-things-considered or summative level are not what is at stake here. The relevant negative existential claim is that Testimony has no bearing on whether Emiliano objectively ought to answer "error theory" (and mutatis mutandis for Duquan). These verdicts about the contributory level are relevant, and are also plausible. Moreover, I am not making the implausible claim that facts about testimony can never be objective reasons for anything; I am making the claim that Testimony is not an objective reason to answer "modal realism"/"error theory." Nor am I making the claim that in no sense is Testimo$n y$ a reason to answer "modal realism"/"error theory." After all, Testimony does bear on whether Duquan and Emiliano did what they subjectively ought to do, and on whether fully informed interlocutors should (a) recognize this, and/or 
(b) criticize them for failing the exam. So Testimony is plausibly a subjective reason for these students to perform these actions. It just is not plausibly a (counterfactual) objective reason for them to do so. ${ }^{23}$

Some may still doubt these verdicts about Testimony et al., so I discuss this more in section 4. For now, let us put such doubts aside and consider the second (and perhaps more interesting and distinct) part of this objection to objectivism. This is the explanation for why, on current forms of objectivism, the relevant embedded proposition-Content — cannot be a subjective reason for Duquan and Emiliano to answer as they did. As I said before, I am not sure whether this proposition is the better candidate for the relevant subjective reason. I just think that there should be a good candidate (in order to explain Datum ${ }_{3}$ ), and if we have ruled out true, complex propositions like Testimony, the natural remaining candidates will be false, simple propositions like Content.

Recall that, for C, Content is a subjective reason for Duquan and Emiliano to answer as they did only if the following holds: if Content were true, it would be an objective reason for Duquan to write "modal realism"/Emiliano to write "error theory." However, Content cannot be true. So the relevant counterfactual will have a necessarily false antecedent. This poses two problems for $\mathrm{C}$. The first is not devastating, but it is a good way to warm up to the second.

The first problem is fairly obvious and immediate. ${ }^{24}$ Say we accept any theory that holds that a counterfactual is vacuously true if its antecedent is necessarily false. For instance, say we take a counterfactual to be true iff its consequent is true in the nearest possible worlds in which its antecedent is true. If there are no possible worlds in which the antecedent is true, the counterfactual is vacuously true. So for $\mathrm{C}$, Content is a subjective reason to do anything. ${ }^{25}$

I do not want to focus on this first problem as I do not think it is devastating. Many balk at the idea that counterfactuals with necessarily false antecedents are vacuously true, and propose that we should fix this bug by considering what is true at the nearest possible or impossible worlds in which the antecedent is true. ${ }^{26}$ This fix avoids getting the wrong results in Duquan's case.

But notice the implications that this fix has when we turn to Emiliano's case.

I am grateful to an anonymous referee for pushing me to further clarify these matters.

The following point was Whiting's main objection to C in "Keep Things in Perspective."

To be clear, the problem here would not be that $\mathrm{C}$ does not get the right result that Content is a subjective reason for Duquan to answer as he did. The problem would be that we get every single wrong result. Content is a subjective reason for Duquan to do literally anything, because any counterfactual with Content as the antecedent is vacuously true.

For general discussion, see Nolan, "Impossible Worlds." 
This is where we get to the second problem, which I do think is devastating. ${ }^{27}$ In the impossible world in which error theory is true, there are no objective reasons whatsoever. In that impossible world, there is no objective reason for Emiliano to answer "error theory," or indeed do anything at all, ever. So we have a subjective reason that could not be an objective reason in any possible or impossible world. What could be worse for $\mathrm{C}$ than the result that some subjective reasons for action are not (im)possible objective reasons for action?

What can objectivists say in response? Some might claim that the objection relies on a false dilemma. Perhaps we should identify subjective reasons by appealing to the agent's desires or goals. ${ }^{28}$ If this is so, then in some cases we will not need to appeal to Testimony or Content. Duquan, for instance, is a bit of a grade-grubber, so the subjective reason in his case might be as follows:

Pass: By answering "modal realism" I will pass the exam.

I doubt that Pass poses problems for objectivists. But note that the corresponding move is not available in Emiliano's case because he is not a grade-grubber. Appealing to the content of his desires or goals leads us right back to Content. So far from being supported by the view that we should identify subjective reasons by appealing to the agent's desires or goals, $\mathrm{C}$ is at odds with that picture when we consider students like Emiliano-or, indeed, professional philosophers who assert that error theory is true and only want to assert the truth. Indeed, C seems to be at odds with any view on which $p$ can be our subjective reason to assert that $p$, which is a surprising and unwelcome result.

Alternatively, some might respond that the objection above is devastating for $\mathrm{C}$, but leaves other forms of objectivism unscathed. You might think that Whiting's view is especially well placed to address this objection, since it is largely motivated by appealing to problems concerning possibility and vacuity. ${ }^{29}$

Interestingly, however, Whiting's view faces the same objection-or at least, an objection with the same structure. For Whiting, $p$ is a subjective reason for $A$ to $\phi$ iff and because $p$ is an epistemically necessary objective reason for $A$ to

27 It might be said that this second problem has the form of the conditional fallacy (Shope, "The Conditional Fallacy in Contemporary Philosophy"), though that is not terribly informative given Shope's "elaborate but somewhat obscure generic formulation of the conditional fallacy” (Bonevac, Dever, and Sosa, “The Conditional Fallacy," 275). If one is tempted by the thought that conditional fallacy-style counterexamples will obviously arise for a counterfactual analysis like $\mathrm{C}$, it is worth reading on to note that the same problem undermines a prominent alternative to counterfactual analyses, namely Whiting's view. I am grateful to John Brunero for suggesting this.

See note 24, above. Whiting neglects the objections below in part because he focuses on counterfactuals involving necessary falsehoods where the truth is knowable a posteriori. 
$\phi$. More perspicuously: $p$ is a subjective reason for $A$ to $\phi$ iff and because it is $a$ priori that, if the facts of the situation are as they appear to $A, p$ is an objective reason for $A$ to $\phi$. Can this view accommodate Datum 3 and Datum ${ }_{4}$ ?

Whiting cannot appeal to Testimony. We saw above that it does not play the right roles to be an objective reason to answer "modal realism"/"error theory." On that same basis, we can say that it is not a priori that if Testimony is truewhich it is, and which it appears to be for Duquan and Emiliano-it is an objective reason to answer "modal realism"/"error theory."

More interestingly, Whiting cannot take Content to be a subjective reason for Duquan and Emiliano to act. Both cases pose difficulties. In Duquan's case, there are technical issues about how to handle necessary truths that are knowable $a$ priori. It is knowable a priori that modal realism is false. On some views, that means that it is epistemically necessary that Content is false, and so epistemically necessary that Content is not an objective reason to do anything.

The more interesting problem is posed by Emiliano's case. Even if it is not epistemically necessary that error theory is false, it is clearly a priori that if things are as they appear to Emiliano-if Content is true-there is no objective reason for him to answer "error theory," or indeed do anything. So for intuitive, nontechnical reasons, Content cannot be Emiliano's reason to answer "error theory." And, more generally, the content of what one asserts cannot be even part of a subjective reason for one to assert that error theory is true.

\section{OUTWEIGHED REASONS}

In section 2 I argued that complex propositions like Probability, Evidence, and Belief are not objective reasons for Carla to take the pill. Similarly, in section 3 I argued that the complex proposition Testimony is not an objective reason for Duquan and Emiliano to answer as they did. These verdicts generate problems for current forms of objectivism, as it makes it tough for current objectivist views to explain how these propositions could be subjective reasons for Carla to take the pill or Duquan and Emiliano to answer as they did. I offered one way to bolster these verdicts by carefully distinguishing them from nearby claims that are either irrelevant or implausible. But given their central role in the objections to current forms of objectivism, more needs to be said to assuage any lingering doubts about these verdicts. In this section I attempt to remedy that.

I suspect that lingering doubts about these verdicts are most likely to turn on a difficulty discussed above - namely, the difficulty of eliciting clear and probative intuitions about whether $p$ is (a) a massively outweighed objective reason for $A$ to $\phi$, or (b) not an objective reason for $A$ to $\phi$. What more can be said to 
bolster my verdicts that in the relevant cases $p$ is not an (outweighed) objective reason?

Here is a way to bolster these verdicts. Do not compare $p$ to paradigm cases of strong or decisive objective reasons for $A$ to $\phi$. Instead, compare $p$ to paradigm cases of massively outweighed objective reasons for $A$ to $\phi$. If this elicits clear and probative intuitions that $p$ does not play the same roles as paradigm cases of massively outweighed objective reasons, that strongly suggests that $p$ is not a massively outweighed objective reason after all. This will be my strategy.

I want to execute this strategy using relatively simple cases and ecumenical resources. So let us return to Anna's case, in which the fact that the red pill will cure her is a decisive objective reason for Anna to take the pill. Holding this fixed, we can elicit helpful intuitive data by comparing two versions of this case:

Mild Nausea: The red pill will also make Anna mildly nauseous.

Misleading Evidence: Anna receives evidence that the red pill will make her mildly nauseous, but this evidence is misleading — it will do no such thing.

In the first version of the case, I take it that the fact that the red pill will make Anna mildly nauseous is a paradigm instance of a massively outweighed objective reason for her not to take the red pill. My intuitions about this case seem clear and probative: this fact is relevant to what she objectively ought to do and what a fully informed interlocutor should advise her to do. Now compare this to Misleading Evidence. The fact that she receives misleading evidence does not play the same roles as our paradigmatic massively outweighed objective reason: it bears on what she subjectively ought to do, but it does not bear on what she objectively ought to do, nor does it bear on whether or not a fully informed interlocutor should advise her to take the red pill.

Since this comparison is between two putative massively outweighed objective reasons, it is hard to see how issues regarding weight could lead us astray here. And, if one wished to contend otherwise, they would face an uphill battle. If there is an objective reason not to take the red pill in Misleading Evidence, presumably we could increase its weight by increasing the strength of the evidence or the intensity of the nausea: such changes do not seem to make this misleading evidence relevant in the way that actual nausea would be relevant. Strong misleading evidence of excruciating nausea still does not seem to bear on what Anna objectively ought to do, or on what a fully informed interlocutor should advise her to do, whereas mild actual nausea does bear on such matters.

If objectivists accept this judgment about misleading evidence in Anna's case, 
surely they should accept similar judgments about misleading evidence-like Testimony and Evidence - in cases like Carla's, Duquan's, and Emiliano's. ${ }^{30} \mathrm{Ob}$ jectivists should want to preserve a distinction between actual countervailing considerations and misleading evidence of countervailing considerations. This suggests that objectivists cannot easily answer the two central objections above by insisting that Testimony et al. are objective reasons for Carla et al. to act.

\section{CONCLUSION AND DIAGNOSIS}

Why do objectivists face these two objections? As was foreshadowed above, my diagnosis concerns an additional commitment that objectivists have taken on without argument: that we must analyze all subjective reasons directly. What does that mean? It means that we must analyze subjective reasons for $A$ to $\phi$ in terms of corresponding objective reasons for that agent to perform that same action. For instance, according to the objectivist views we have considered, $p$ is a subjective reason for Carla to take the pill only if $p$ is counterfactually an objective reason for Carla to take the pill (counterfactual analyses); Carla is competently attracted to treating $p$ like an objective reason to take the pill (Sylvan's view); or $p$ is an epistemically necessary objective reason for Carla to take the pill (Whiting's view). By taking on this commitment, objectivists have occupied a fairly narrow region of logical space. And the two objections above reveal that it is also a fairly unappealing region of logical space.

Consider the first objection. We saw that Probability is the most plausible candidate for a subjective reason for Carla to take the pill. The problem was not that it cannot be an objective reason per se. It was that Probability does not play the right roles to be a counterfactual (and hence actual) objective reason for Carla to take the pill, and Carla cannot competently treat it as an objective reason to take the pill. This problem is compounded because on these objectivist views no other proposition is a good candidate for being the subjective reason for Carla to take the pill, so objectivists struggle to explain intuitive data points.

Now consider the second objection. We saw that Testimony is a plausible candidate for a subjective reason for Emiliano to answer "error theory." Again, the problem is not that this proposition cannot be an objective reason per se. It is that this proposition is not a plausible candidate for a counterfactual or epis-

It is worth noting here that Julia Markovits has defended a similar view: "If expert testimony gives us most reason to believe some act would be best then that testimony is the reason we ought to perform that act," even if that testimony is misleading; but as she argues, these "moral reasons for us to perform some action are subjective" and not objective reasons (Markovits, “Saints, Heroes, Sages, and Villains," 306-7). 
temically necessary objective reason for Emiliano to answer "error theory." This problem is compounded because objectivists cannot take the false content of that testimony to be a subjective reason for Emiliano to answer as he did, so once again objectivists struggle to accommodate intuitive data points.

This does not show that we cannot analyze subjective reasons in terms of objective reasons. It suggests that we cannot analyze all subjective reasons for $A$ to $\phi$ directly, in terms of objective reasons for $A$ to $\phi$. So the problem is not that objectivism is false, but that it has been construed narrowly, and naïvely.

Interestingly, this diagnosis dovetails nicely with a lesson Frank Jackson drew a long time ago about the relation between objective and subjective normative notions. Jackson noticed that, in some cases involving uncertainty, we subjectively ought to $\phi$ even though we know that it is definitely not the case that we objectively ought to $\phi$. Jackson took this to show that naive views that derived subjective oughts directly from objective oughts were problematic; instead, we should adopt a "decision-theoretic" view about the subjective ought. ${ }^{31}$

Some details of Jackson's own view are not compatible with objectivism. But they do not concern us. The interesting point is that objectivists could offer a decision-theoretic explanation of the subjective reasons for Carla and Emiliano to $\phi$ in terms of objective reasons for credences and preferences.

That explanation would require many moving parts that warrant independent motivation and extensive discussion. I will not delve into those details here. All that I hoped to do here is motivate the exploration of neglected areas of logical space: objectivists can and should seek to analyze some subjective reasons for action indirectly, in terms of objective reasons for attitudes. ${ }^{32}$

Virginia Tech dwodak@vt.edu

\section{REFERENCES}

Bonevac, Daniel, Josh Dever, and David Sosa. "The Conditional Fallacy." Philosophical Review 115, no. 3 (July 2006): 273-316.

Dancy, Jonathan. “The Particularist's Progress.” In Moral Particularism, edited by

31 Jackson, "Decision-Theoretic Consequentialism and the Nearest and Dearest Objection."

32 Many thanks to John Brunero, Pete Graham, Frank Jackson, Nicholas Laskowski, Errol Lord, Philip Pettit, Douglas Portmore, Pamela Robinson, Gideon Rosen, Michael Smith, several anonymous reviewers, and audiences at the University of Southampton and the 2016 American Philosophical Association Central Division Meeting. 
Brad Hooker and Margaret Little, 130-56. Oxford: Oxford University Press, 2000.

Dorsey, Dale. "Objective Morality, Subjective Morality, and the Explanatory Question." Journal of Ethics and Social Philosophy 6, no. 3 (2012): 1-24.

Hawthorne, John, and Jason Stanley. "Knowledge and Action." Journal of Philosophy 105, no. 10 (October 2008): 571-90.

Jackson, Frank. "Decision-Theoretic Consequentialism and the Nearest and Dearest Objection.” Ethics 101, no. 3 (April 1991): 461-82.

Markovits, Julia. "Saints, Heroes, Sages, and Villains." Philosophical Studies 158, no. 2 (March 2012): 289-311.

Lord, Errol. "The Coherent and the Rational." Analytic Philosophy 55, no. 2 (June 2014): 151-75.

_- "Having Reasons and the Factoring Account." Philosophical Studies 149, no. 3 (July 2010): 283-96.

—. "What You're Rationally Required to Do and What You Ought to Do (Are the Same Thing!)." Mind (forthcoming).

Nolan, Daniel. "Impossible Worlds." Philosophy Compass 8, no. 4 (April 2013): 360-72.

Parfit, Derek. On What Matters. 2 vols. Oxford: Oxford University Press, 2011.

Schiffer, Stephen. "Interest-Relative Invariantism." Philosophy and Phenomenological Research 75, no. 1 (July 2007): 188-95.

Schroeder, Mark. "Having Reasons." Philosophical Studies 139, no. 1 (April 2008): 57-71.

- "Means-End Coherence, Stringency, and Subjective Reasons." Philosophical Studies 143, no. 2 (March 2009): 223-48.

- Slaves of the Passions. Oxford: Oxford University Press, 2007.

. "What Does It Take to 'Have' a Reason?" In Reasons for Belief, edited by Andrew Reisner and Asbjorn Steglich-Petersen, 201-22. Cambridge: Cambridge University Press, 2011.

Shope, Robert. "The Conditional Fallacy in Contemporary Philosophy." Journal of Philosophy 75, no. 8 (August 1978): 397-413.

Sylvan, Kurt. "What Apparent Reasons Appear to Be." Philosophical Studies 172, no. 3 (March 2015): 587-606.

Vogelstein, Eric. "Subjective Reasons." Ethical Theory and Moral Practice 15, no. 2 (April 2012): 239-57.

Way, Jonathan. "Two Accounts of the Normativity of Rationality." Journal of Ethics and Social Philosophy (December 2009).

Wedgwood, Ralph. “The Pitfalls of 'Reasons.'” Philosophical Issues 25, no. 1 (October 2015): 123-43. 
Whiting, Daniel. "Keep Things in Perspective: Reasons, Rationality and the A Priori." Journal of Ethics and Social Philosophy 8, no. 1 (2014): 1-22. 